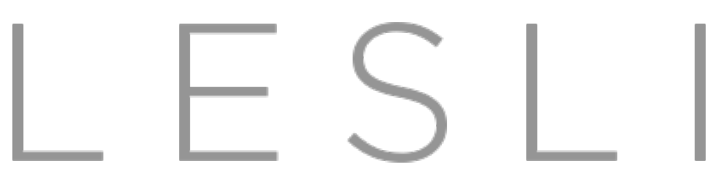

Linguistic Evidence in Security, Law and Intelligence

Volume 1, No. 1 (2013) | ISSN 2327-5596 (online) | DOI 10.5195/lesli.2013.7 | http://lesli-journal.org

\title{
An Editorial Note for LESLI 1:1
}

\author{
Carole E Chaski PhD \\ Editor, LESLI \\ Executive Director, Institute for Linguistic Evidence, USA
}

Welcome to the first volume and issue of Linguistic Evidence in Security, Law and Intelligence (LESLI), the journal of the Institute for Linguistic Evidence and its membership organization TALE: The Association for Linguistic Evidence. In this issue, our readers can contemplate deception from multiple perspectives.

Accurate and reliable deception detection is a Holy Grail to all kinds of professions that require interviewing or surveillance: law enforcement, private investigation, executive and corporate security, national and business intelligence, clinical psychology and human resources management. In this issue, four research articles tackle deception detection, with reporting of empirical research results.

Amela, Valencia-Garcia and Cantos' "Seeing through Deception: A Computational Approach to Deceit Detection in Spanish Written Communication" applies a text-analytic approach to deception detection based on Pennebaker's LIWC (Linguistic Inquiry and Word Count) software to a new dataset, Spanish texts. Amela, Valencia-Garcia and Cantos also provide a good overview of this approach that readers unfamiliar with the word-based approach will appreciate. Interestingly, another popular approach to text analysis, known as bag-of-words, did not perform as well as the LIWC approach, suggesting that certain word categories are important to deception detection in Spanish, as it has been shown in English. Replication studies are essential for scientific progress: Amela, Valencia-Garcia and Cantos' article is both replication and a nice contrast between the two competing approaches.

Skillicorn and Lamb, who also provide a clear overview of the LIWC-based approach to deception detection, extend this approach in "Extending Textual Models of Deception to Interrogation Settings." Since Skillicorn and Lamb use datasets comprised of question-answer dialog, each speaker's linguistic strategy is determined in response to another person's language, automatically affecting word usage and kinds of responses. Skillicorn and Lamb take linguistic analysis beyond the word level: language is, after all, far more than a list (or bag) of words, demonstrating an interesting link between word choice and conversational structure. Their research shows how the LIWC-based approach can be improved, and they offer empirically-based advice to interrogators on question-formation.

\section{$(\mathrm{cc}) \mathrm{Er}$}

Articles in this journal are licensed under a Creative Commons Attribution 3.0 United States License.

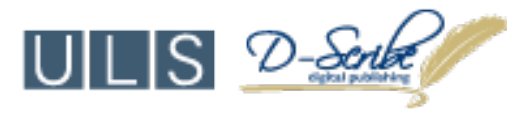

This journal is published by the University Library System, University of Pittsburgh as part of its D-Scribe

Digital Publishing Program and is cosponsored by the University of Pittsburgh Press. 
Going beyond the word and sentence level, Picornell presents a novel application of narrative structure to deception detection, in "Analysing Deception in Written Witness Statements". Her article presents the rationale for applying episodic analysis to written texts with deceptive content, reports a high accuracy rate, and has presented a novel way to handle deception detection. Picornell's hypothesis certainly warrants replication and we look forward to seeing the scholarship that will follow.

Collister's "Detection of Deception in a Virtual World" takes an interactional perspective on identity and deception in a world that is comprised to a large degree of conversation, the virtual world of Internet gaming. Collister provides three levels of analysis for identity and deception management in this virtual world. Intelligence analysis should certainly consider Collister's approach, especially since the cyberworld is populated by those who are not who they seem to be.

Another perspective on deception is provided in Cole, Teboul, Zulawski, Wicklander and Sturman, in "False Confessions and the Use of Incriminating Evidence". False confession appears to be, on the one hand, selfdeception or, on the other hand, believing deception about incriminating evidence. By changing one aspect of the experimental design that is used to demonstrate the ease of creating false confession, Cole, Teboul, Zulawski, Wicklander and Sturman show empirically that subjective awareness of the interrogated can add a new explanation to the puzzle of why people confess to crimes they did not commit, and why other people never fall for the deception based on phony incriminating evidence. False confession is a frightening fact of criminal justice systems throughout the world, and clearly a grave concern to interrogators. Cole, Teboul, Zulawski, Wicklander and Sturman's work can provide realistic guidelines to interrogators and also eventually lead to an assessment of interrogatees that protects the interrogation system from false confession.

It is a real pleasure to have our first policy paper authored by Harry Hollien, one of the most well-respected and productive researchers in forensic speaker identification. In "Barriers to Progress in Speaker Identification, with Comments on the Trayvon Martin Case", Hollien provides an excellent overview of the field of forensic phonetics, and how the field can protect itself from "wannabes." Wannabes are, in one sense, deluded about their skills, and this kind of delusion intruded into the Trayvon Martin case, providing an example of how essential fundamental, litigation-independent research is in the field of forensic linguistics (including phonetics).

Finally, in a resource essay, Chaski describes the ILER platform, software that enables researchers to collect data electronically from vetted users. While the Internet contains billions of words, there is precious little ground truth data that is naturalistic enough to be used realistically in the development of forensic linguistic methods. ILER can help researchers collect ground truth data via the Internet.

Thank you for reading LESLI! 